\title{
The Impact of Bevacizumab (Avastin) on Survival in Metastatic Solid Tumors - A Meta-Analysis and Systematic Review
}

\author{
Limor Amit $^{1 *}$, Irit Ben-Aharon ${ }^{1}$, Liat Vidal ${ }^{2}$, Leonard Leibovici ${ }^{3}$, Salomon Stemmer ${ }^{1}$ \\ 1 Institute of Oncology, Davidoff Center, Rabin Medical Center, Beilinson Campus, Petach Tiqwa, Israel and the Sackler School of Medicine, Tel-Aviv University, Israel, \\ 2 Institute of Hematology, Davidoff Center, Rabin Medical Center, Beilinson Campus, Petach Tiqwa Israel and the Sackler School of Medicine, Tel-Aviv University, Israel, \\ 3 Medicine E Rabin Medical Center, Beilinson Campus, Petach Tiqwa, Israel and the Sackler School of Medicine, Tel-Aviv University, Israel
}

\begin{abstract}
Purpose: To evaluate the effect of Bevacizumab in combination with chemotherapy on overall survival of patients with metastatic solid tumors.

Design: A systematic literature search to identify randomized trials comparing chemotherapy with and without Bevacizumab in metastatic cancer. The primary end point was overall survival (OS) and the secondary end points were progression free survival (PFS) and toxicity. A meta-analysis was performed for each tumor type and for the combination of all tumors.

Results: 24 randomized trials with 8 different types of malignancies were included in this meta-analysis. Patients treated with Bevacizumab had an OS benefit, hazard ratio (HR) 0.89 (95\% Cl $\left.0.84-0.93, \mathrm{P}<0.00001 \mathrm{I}^{2}-4 \%\right)$. The combined analysis showed a PFS benefit with a HR 0.71 (95\% Cl 0.68-0.74, P<0.00001, $\left.\mathrm{I}^{2}-54 \%\right)$. The toxicity analysis showed a statistically significant increase in fatal adverse events (FAEs) in the Bevacizumab treatment arm, risk ratio (RR) 1.47 (95\% Cl 1.1-1.98). A separate analysis of the lung cancer trials showed an increased risk of fatal pulmonary hemorrhage with a $\mathrm{RR}$ of 5.65 (95\% $\mathrm{Cl}$ 1.26-25.26). The risk of G3-4 adverse events was increased: RR 1.2 (95\% Cl 1.15-1.24).

Conclusion: in this combined analysis Bevacizumab improved OS (with little heterogeneity) and PFS. These results should be considered in the light of lack of markers predictive of response and the increased severe and fatal toxicity seen with Bevacizumab treatment.
\end{abstract}

Citation: Amit L, Ben-Aharon I, Vidal L, Leibovici L, Stemmer S (2013) The Impact of Bevacizumab (Avastin) on Survival in Metastatic Solid Tumors - A MetaAnalysis and Systematic Review. PLoS ONE 8(1): e51780. doi:10.1371/journal.pone.0051780

Editor: Jose Luis Perez-Gracia, University Clinic of Navarra, Spain

Received July 11, 2012; Accepted November 12, 2012; Published January 22, 2013

Copyright: ( $) 2013$ Amit et al. This is an open-access article distributed under the terms of the Creative Commons Attribution License, which permits unrestricted use, distribution, and reproduction in any medium, provided the original author and source are credited.

Funding: There was no financial support for this study.

Competing Interests: Dr Salomon Stemmer is an academic editor of PLOS. This does not alter the authors' adherence to all the PLOS ONE policies on sharing data and materials.

*E-mail: limor.amit@gmail.com

\section{Introduction}

Neovascularization is one of the main mechanisms for the progression of human solid tumors and also provides a pathway for the migration of tumor cells by accessing the systemic circulation to establish distant metastases. Vascular endothelial growth factor (VEGF) plays an essential role in angiogenesis [1-5]. Bevacizumab is a humanized monoclonal antibody that blocks the binding of VEGF to its receptors and results in regression of immature tumor vasculature, normalization of remaining tumor vasculature and inhibition of further tumor angiogenesis [6]. The complete mechanism of angiogenesis inhibition is not entirely understood. Due to the proposed universal anti-tumor activity of Bevacizumab it was widely studied in the treatment of early and metastatic tumors.

Several randomized controlled trials have evaluated the role of Bevacizumab in addition to chemotherapy for patients with metastatic colorectal cancer [7-13]. A recent meta-analysis found a statistically significant median OS advantage for patients with metastatic colorectal cancer of 20.5 months with Bevacizumab compared with 17.7 months without - with a hazard ratio (HR) for overall survival (OS) of 0.81 and for progression free survival (PFS) of 0.6 [14].

The role of angiogenesis is established in the progression of lung cancers [15]. Four randomized controlled studies [16-20] evaluated the role of Bevacizumab in metastatic NSCLC yielding conflicting results in terms of survival benefit. The first study showed that squamous cell (SCG) histology had a high risk for fatal (mostly bleeding) events when treated with Bevacizumab. Therefore the following trials excluded patients with SCG. The ECOG 4599 study showed a survival advantage for Bevacizumab combined with Carboplatinum and Paclitaxel. The AVAIL study combined Bevacizumab with Cisplatinum and Gemcitabine (which is less effective in adenocarcima [21]) and showed a very small PFS advantage and no OS benefit. Following those studies the FDA approved the use of Bevacizumab in metastatic adenocarcinoma of lung. 
In metastatic breast cancer patients, few randomized controlled trials appraised the use of Bevacizumab as first-line treatment in combination with chemotherapy agents. In general these studies showed improvement in tumor response rate and PFS but not OS [22-31]. The combination of Taxanes or Capecitabine with Bevacizumab until progression seems to result in the best PFS in this setting. Another recent metaanalysis in metastatic breast cancer failed to show a significant benefit in OS [32]. Therefore the FDA has recently revoked the recommendation for the use of Bevacizumab in first line metastatic breast cancer.

Bevacizumab is an attractive option for metastatic renal cell carcinoma because of the correlation between VEGF and von Hippel Lindau (VHL) tumor suppressor gene, which has a substantial role in the mechanism of the disease. Two phase III trials were performed [33-37] evaluating the role of Bevacizumab in combination with INF $\alpha$ compared to INF $\alpha$ alone. These trials showed a PFS benefit but no OS advantage.

In pancreatic cancer, two phase III studies combining Gemcitabine with Bevacizumab showed negative results with no increase in OS [38-39].

VEGF expression is a negative prognostic factor for survival in patients with gastric cancer. A preliminary phase II trial showed encouraging results [40], but the phase III trial showed a significant ORR benefit $(46 \%$ vs $37 \%, \mathrm{P}=0.0315)$ without survival benefit [41].

In metastatic castrate resistant prostate cancer (mCRPC) patients preclinical activity of VEGF blockade and inverse relationship of plasma and urine VEGF levels and survival suggested that VEGF blockade was an appropriate potential strategy. A recent phase III trial evaluated approximately 1000 patients and failed to show a significant OS benefit [42].

Malignant melanoma is a highly vascular tumor in which VEGF is expressed and seems to play a role in disease progression. BEAM - a randomized phase II study in patients with previously untreated metastatic melanoma compared Carboplatinum and Paclitaxel with and without Bevacizumab [43]. This trial did not reach its primary objective of statistically significant improvement in PFS.

Due to the non specific mechanism of action of Bevacizumab in solid tumors and the conflicting overall survival results, we aimed to perform a meta-analysis of all available data regarding the efficacy and toxicity of Bevacizumab in metastatic solid tumors. A significant effect without heterogeneity across all tumor types would increase the confidence in the efficiency of Bevacizumab.

\section{Methods}

\section{Outcome measures}

The primary outcomes of this meta-analysis were overall survival (OS), defined as time from randomization to death; and progression free survival (PFS) defined as the continued survival in the absence of evidence for progression of disease. Secondary outcomes were response rate $(\mathrm{RR})$ - the percentage of patients achieving a complete response or a partial response defined by RECIST criteria (Response Evaluation Criteria in Solid Tumors) and toxicity. Toxicity was defined as grade $>2$ (hematological and non-hematological), including adverse events that may be typical to Bevacizumab (as hypertension and vascular events). The number of events was divided by number of patients analyzed.

\section{Literature search}

Relevant randomized clinical trials were identified by searching The Cochrane Library (12/2011), MEDLINE (January 1966 to Dec 2011) and LILACS (12/2011). The terms 'Bevacizumab OR
Avastin' and similar, and 'cancer' and similar were crossed (see appendix S1 for search strategy). A search for abstracts was performed in the proceedings of the following conferences: American society of clinical oncology (ASCO), European society of medical oncology (ESMO) and San Antonio Breast Cancer Symposium. National cancer institute was searched 12/2011 for any ongoing trials. References of selected articles were reviewed for any additional relevant trials, and original authors were contacted for possible unpublished data.

\section{Inclusion criteria}

We included all randomized controlled trials that compared the addition of bevacizumab to various chemotherapy protocols without Bevacizumab in adult patients with metastatic cancer in the first and second line setting seperately. We excluded brain tumors due to the different drug delivery through the blood brain barrier and due to its role in reducing edema around the tumor [56]. We also excluded ovarian cancer as the trials included metastatic and non metastatic disease. We excluded maintenance therapy trials and phase II non randomized and phase IV trials. Trials in which the primary outcome measure of OS was not reported were included if all other inclusion criteria were met. Trials assessing toxicity alone were excluded.

\section{Data extraction}

Two reviewers independently applied inclusion criteria, selected the studies, and extracted data and outcomes. In case of disagreement between the two reviewers, a third reviewer extracted the data. Authors of studies were contacted when clarification was needed or for providing complementary data.

\section{Quality assessment}

Trials fulfilling the review inclusion criteria were assessed for methodological quality by two reviewers. For RCTs, data regarding randomization and allocation concealment, blinding, sample size, exclusions after randomization, and different lengths of follow-up were performed using the criteria described in the Cochrane Reviewer's handbook.

\section{Statistical methods}

Hazard ratios (HR) and variances for time to event outcomes were estimated as described by Parmar et al, and pooled according to inverse of variance method (Review Manager [RevMan], version 5 for Windows; The Cochrane Collaboration, Oxford, United Kingdom). Pooled relative risk (RR) and 95\% confidence intervals (CI) for dichotomous data were estimated using the Mantel-Haenszel method. The confidence intervals for OS from three studies were calculated from the published Kaplan Mayer curves $[7,12,17]$. We assessed heterogeneity in the results of trials by inspection of their graphical presentations and by calculating a $\mathrm{Chi}^{2}$ test of heterogeneity and the $I^{2}$ measure of inconsistency. Significant heterogeneity was defined as a $\mathrm{Chi}^{2}$ test $P<.1$ or an $I^{2}$ measure greater than $50 \%{ }^{17}$. We used a fixed effect model to pool results except in the event of significant heterogeneity when random-effects model was used (inverse of variance method and DerSimonian and Laird method). Analysis was performed for all included studies and for each cancer type for each available outcome.

For calculating number needed to harm $(\mathrm{NNH})$ in order to evaluate the additive effect of Bevacizumab on the absolute risk for grade 3-4 adverse events, we retrieved the data on the incidence data of grade 3-4 adverse events in each arm (Bevacizumab versus 
control). Risk was calculated by multiplying the absolute risk of the control arm by (1-RR for fatal adverse events).

\section{Results}

Our primary search yielded 3615 publications of which 1376 were reviews. We excluded 2212 publications as not relevant, leaving 27 publications for 24 relevant studies to this analysis (figure 1). The included studies were randomized phase II or phase III studies of Bevacizumab in combination with chemotherapy in the metastatic setting. Study characteristics are presented in table 1. One study [9] was eventually excluded from the efficacy analysis but included in the toxicity analysis as survival data was lacking.

\section{Efficacy}

OS analysis included 19 trials and 11,422 patients with metastatic solid tumors treated with chemotherapy alone or with Bevacizumab and yielded a significant effect in OS favoring Bevacizumab, HR 0.89 (95\% CI 0.84-0.93 P<0.00001) with low heterogeneity $\mathrm{I}^{2}=4 \%$.

A PFS analysis of 17 of these trials including 10,746 patients (data from the CALGB pancreatic cancer trial on PFS was not

\section{$\underline{\text { study search }}$}

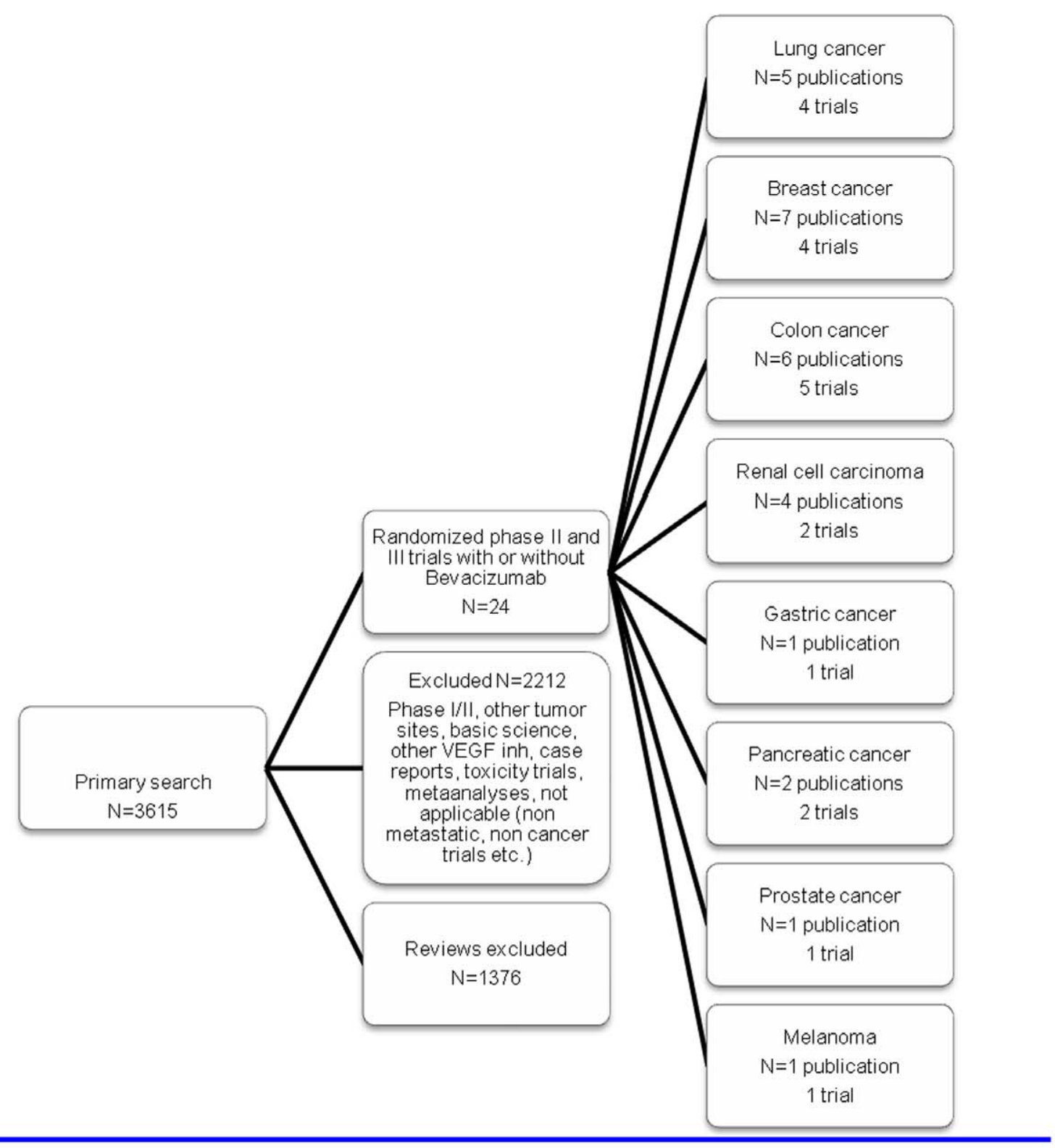

Figure 1. Trial selection.

doi:10.1371/journal.pone.0051780.g001 


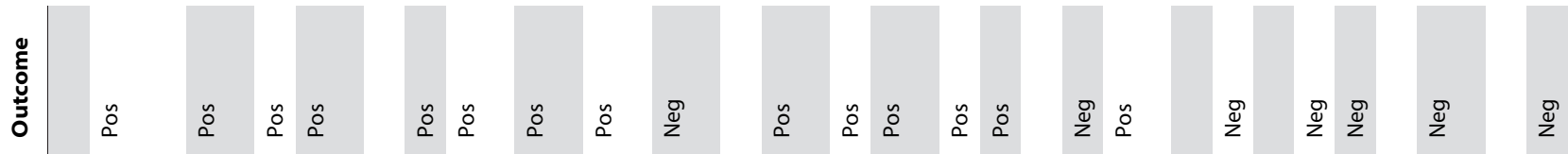

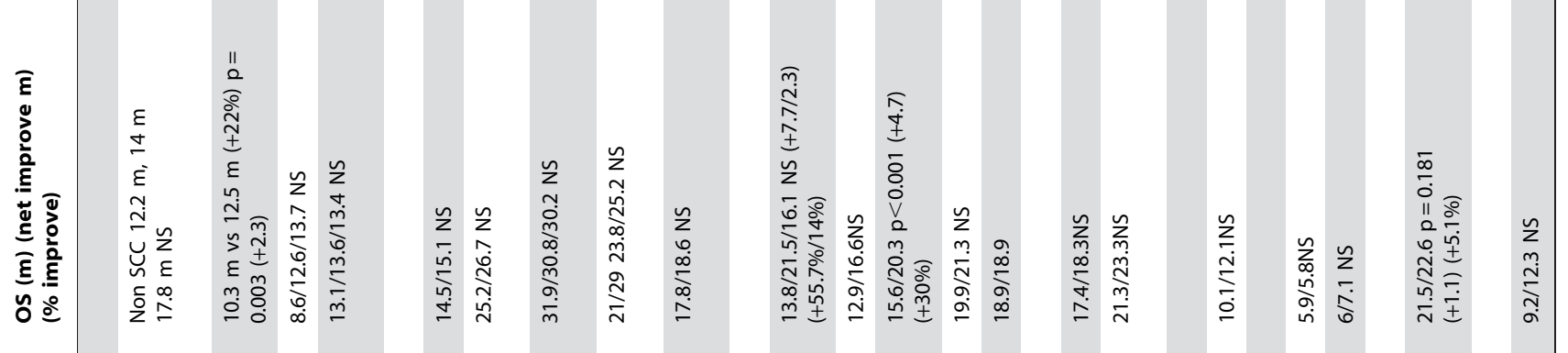

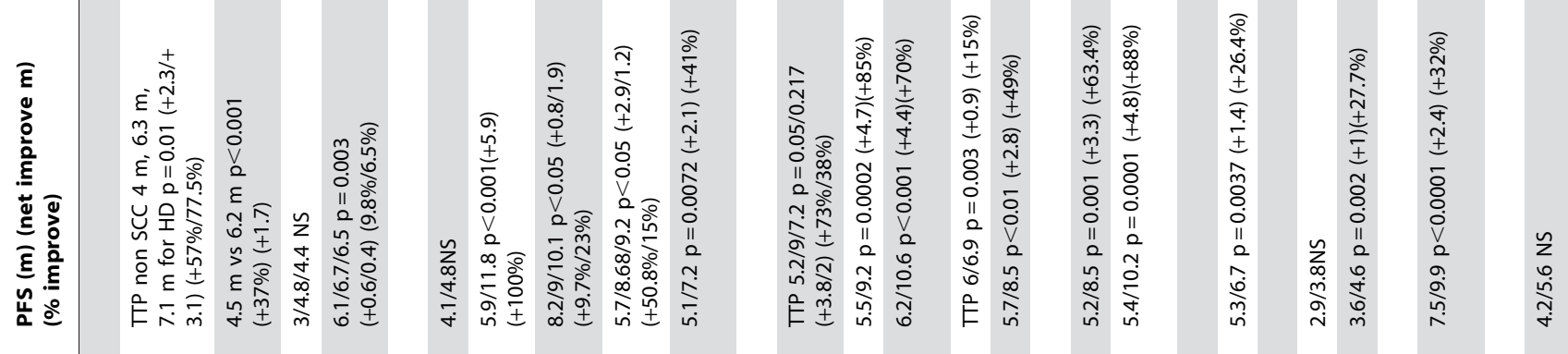

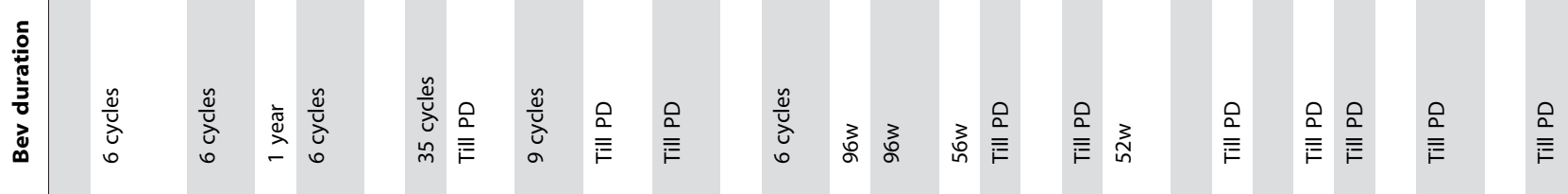

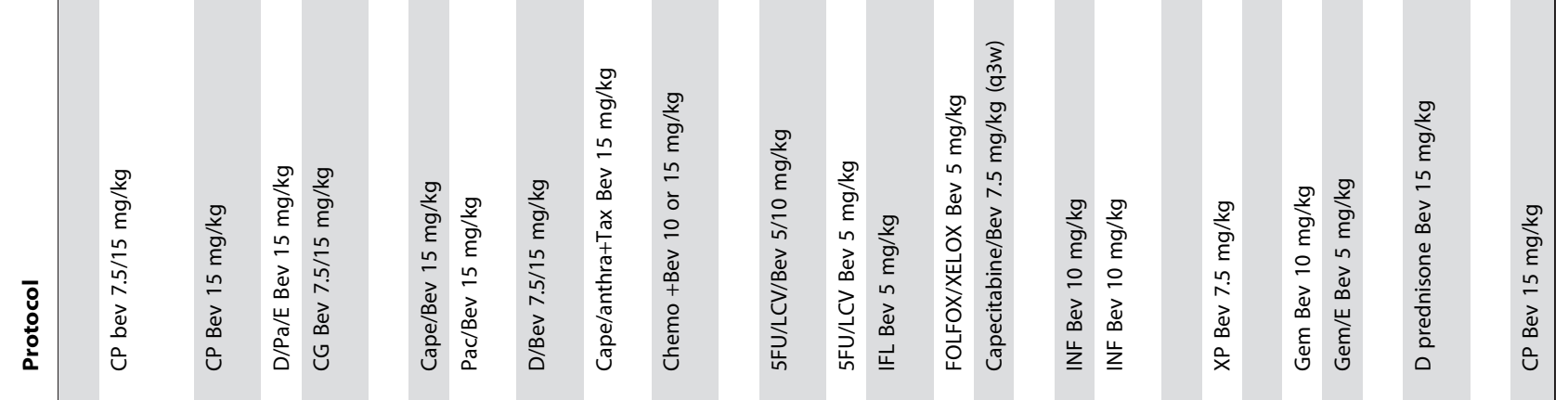

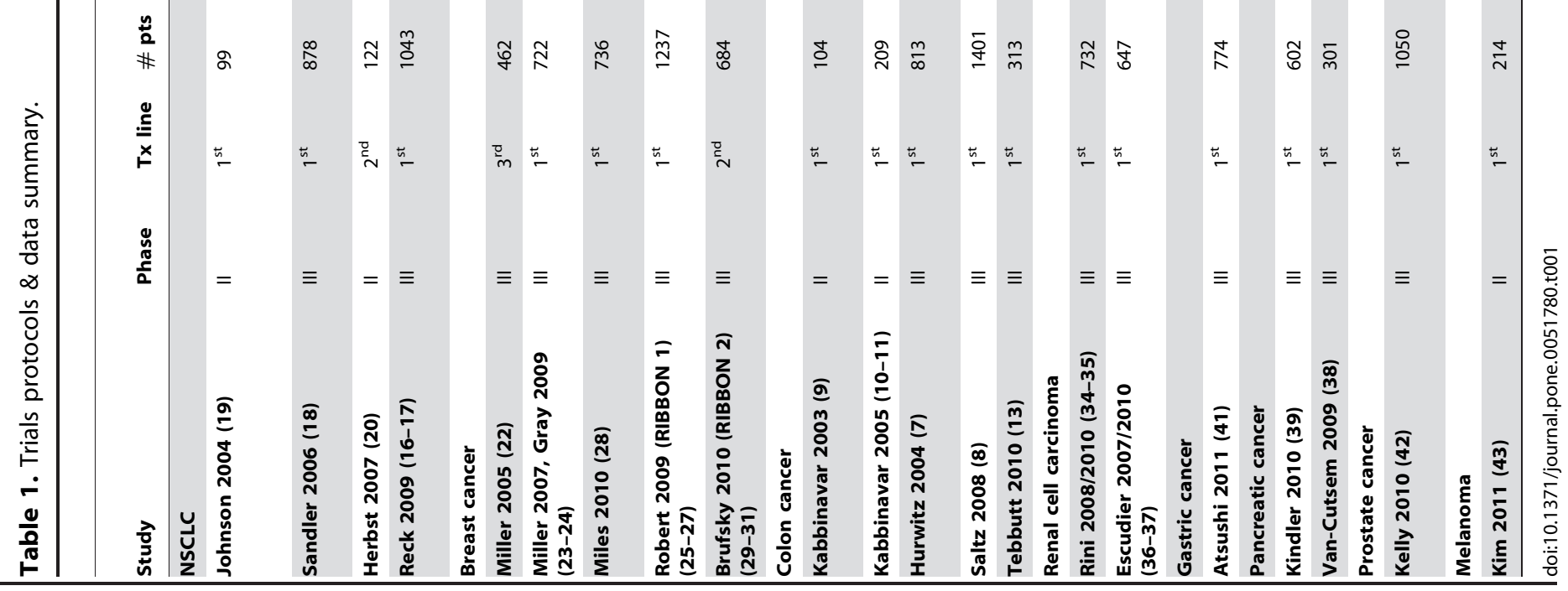




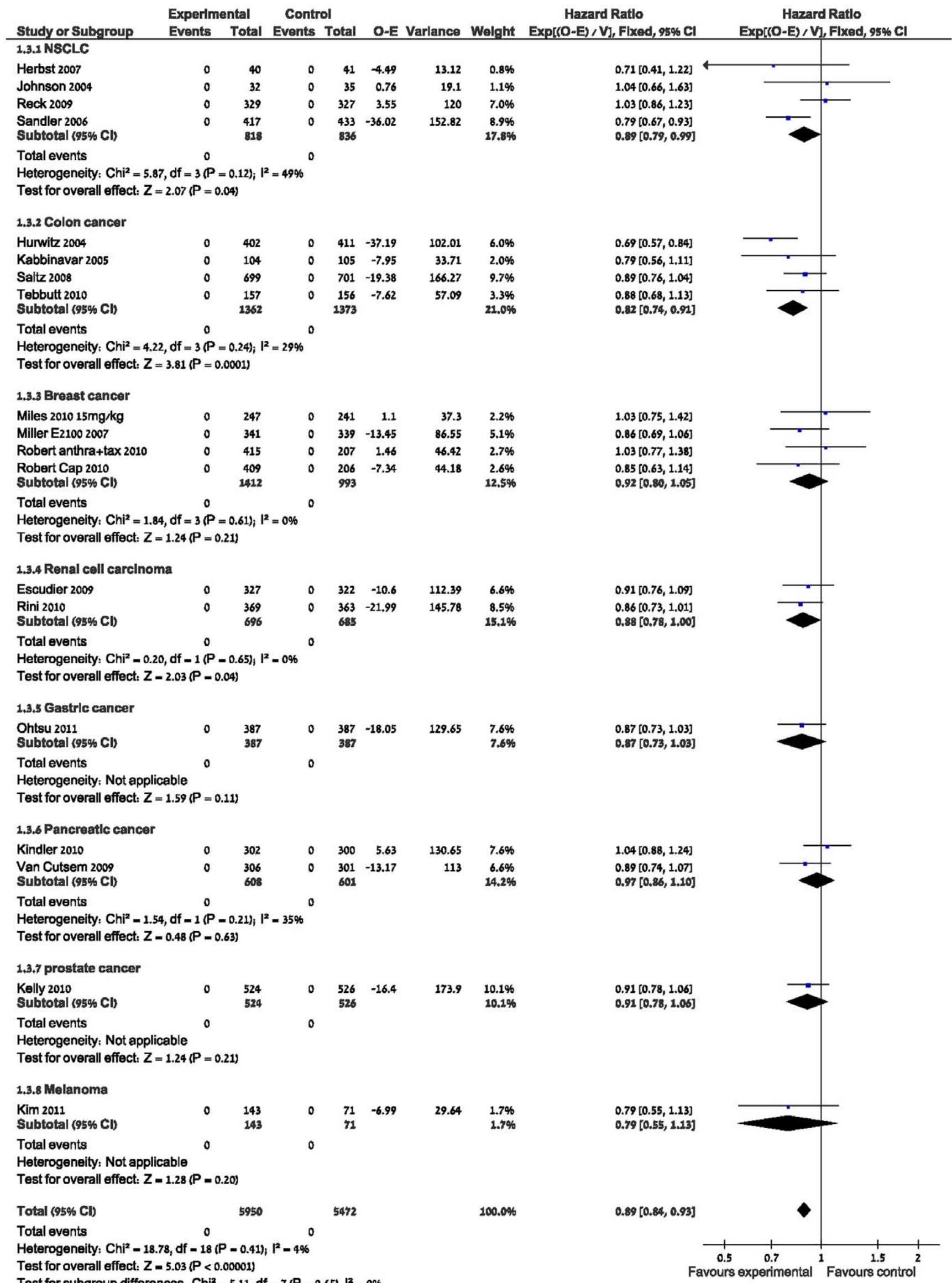


published) showed a significant PFS benefit but with high heterogeneity, HR $0.71 \quad(95 \%$ CI $0.68-0.74, \quad \mathrm{p}<0.00001$ $\mathrm{I}^{2}=54 \%$ ). (Figures 2,3).

Second line treatment in breast cancer (figures $4 \mathrm{a}, 4 \mathrm{~b}$ ) showed a borderline PFS advantage but no OS advantage.

\section{Adverse events}

A meta- analysis of adverse events (AE) (table 2) showed a statistically significant increase in fatal adverse events (FAEs) in the Bevacizumab treatment arms RR 1.48 (95\% CI 1.11-1.98). A separate analysis of the lung cancer trials including mainly adenocarcinoma, showed an increased risk of fatal pulmonary hemorrhage with a RR of 5.65 (95\% CI 1.26-25.26).

This analysis also showed an increased risk for adverse events G3-4 with Bevacizumab treatment compared with chemotherapy alone. There were 1981 events in the Bevacizumab group compared to 1619 events in the control group, RR 1.2 (95\% CI 1.15-1.24). The main AEs were: hypertension (HTN) RR 4.96 (95\% CI 3.82-6.44), proteinuria RR 7.08 (95\% CI 4.54-11.04), hemorrhage RR-1.34 (95\%CI 1.02-1.76) and GI perforation RR 2.3 (95\% CI 1.34-3.95). There was no significant risk of venous thromboembolic events. Regarding arterial thromboembolic events there was no increased risk in the combined analysis but there was an increased risk in breast cancer patients RR $5.97(95 \%$ CI 1.07-33.22) and in RCG patients RR 6.55 (95\%CI 1.5-28.59).

\section{Discussion}

The present systematic review and meta-analysis indicates that the addition of Bevacizumab to chemotherapy in patients with metastatic solid tumors resulted in a statistically significant improvement of OS and PFS. The OS benefit was significant and homogenous, with a HR 0.89 (95\% CI; 0.84-0.93 P<0.00001, $\left.\mathrm{I}^{2}-4 \%\right)$ The effect on OS was similar for all malignancies, except for breast cancer.

The PFS benefit was significant with a HR 0.71 (95\%CI 0.68$0.74 \mathrm{P}<0.00001 \mathrm{I} 2-54 \%$ ) but with high heterogeneity attributed to the NSCLC, colon and RCG trials.

There may be several potential explanations for the heterogeneity in PFS.

First, cessation of Bevacizumab treatment may lead to a rebound effect of angiogenesis, [5]. This effect might explain the different results and heterogeneity of the breast cancer trials. The E2100 breast cancer trial continued Bevacizumab until progression as compared with the AVADO breast cancer trial that gave only nine cycles of Bevacizumab. This hypothesis may justify the continuation of Bevacizumab beyond progression [23-24,28] that it is currently under evaluation (Ribbon 3).

Second is the lack of predictive markers for Bevacizumab treatment. Hypertension (HTN) is known to develop in up to $30 \%$ of patients treated with Bevacizumab. Retrospective subgroup analyses have appraised the predictive value of HTN as a biomarker for response to Bevacizumab in breast and colon cancer, and have shown correlation with response but not with survival benefit [44]. A subgroup analysis of the RCC CALGB trial demonstrated a significant median OS benefit in patients with HTN $\geq$ grade 2 (according to the CTCAE 3 ) of 41.2 months versus 16.2 months in patients without HTN $\mathrm{P}<0.001$ [44-46]. This putative correlation has not been evaluated in the large colon cancer studies. Other predictive parameters such as VEGF levels, vascular density or VEGF polymorphisms and molecular markers could also serve as markers of response to Bevacizumab. In the E2100 Breast cancer trial, VEGF polymorphisms (VEGF-2578 $\mathrm{AA}$ and VEGF-1154 AA) genotypes were associated with a superior median OS in the Bevacizumab arm compared with other genotypes (37 months and 46 months respectively compared to 25 months in the control arm) [47].

Third, the difference in the results may lie in the chemotherapy agents combined with Bevacizumab: It has been postulated that Paclitaxel given on a frequent basis also exhibits antiangiogenic and pro-apoptotic effects (partially by down-regulation of VEGF), thereby enhancing efficacy. [48]. The different result of the E2100 and the AVADO trials (breast cancer) may also be a result of the Taxane protocol used - weekly Paclitaxel as opposed to three weekly Docetaxel, an effective but toxic regimen.

In the lung cancer trials Bevacizumab again demonstrated superior OS when combined with a taxane based regimen as opposed to a gemcitabine based regimen [17-18].

In colon cancer trials the heterogeneity could also be explained by the different chemotherapy regimens. In Hurwitz et al; [7] the chemotherapy regimen used was IFL, known to be a toxic regimen and now rarely used whereas Saltz et al; [8] added Bevacizumab to FOLFOX.

Regarding colon cancer our results are supported by other meta-analyses evaluating the addition of Bevacizumab to chemotherapy in the metastatic setting [14,49-51]

These should be interpreted in the light of the disease specific survival of the different maligancies. Therefore 3 months of survival benefit in metastatic colon cancer where the expected OS is more than 20 months differs from a three months benefit in a patient with metastatic lung or pancreatic cancer in which the median survival is less than a year [52].

The role of PFS as a surrogate for overall survival has been greatly debated in metastatic cancer. The multiple effective treatment options may explain the lack of OS advantage. Broglio et al assumed that OS represented the sum of PFS and survival post progression (SPP). He assumed that SPP contributes more to OS than PFS, therefore when SPP is 2 months there is a greater than $90 \%$ chance of detecting a statistically significant OS benefit but when SPP is 24 months there is a less than $20 \%$ chance of detecting a statistically significant OS benefit. Accordingly, breast cancer serves as a protoype for a long SPP and therefore no OS benefit was seen in these studies as compared with NSCLC with a short SPP [53].

Another important issue is that when improvements in OS are observed, their impact should be assessed considering the effect of treatment on the quality of life of the patient. Our toxicity analysis (table 2) shows an increase in adverse events $>$ G2 RR-1.26, and fatal adverse events RR-1.47 with and increased risk for fatal pulmonary hemorrhage in the lung cancer trials with a RR-5.65. Our analysis also suggested that the most significant risk of FAEs was in patients with prostate and lung cancer, as reported by others [54]. Our analysis showed no increased risk of venous thromboembolic events, in concordance with another recently published meta-analysis [55].

Moreover our analysis showed that the different serious adverse events seemed to be more prevalent in certain tumors compared to others: G3-4 adverse events were more common with NSCLC, colon and gastric cancer. HTN was significant in all cancer types but was most significant in breast cancer with a RR-17.63, proteinuria was also significant in all types but not in gastric and colon cancer, hemorrhage was significant only in RCG, and GI 


\begin{tabular}{|c|c|c|c|c|c|c|c|c|c|c|}
\hline Study or Subgroup & \multicolumn{2}{|c|}{ Experimental } & \multicolumn{2}{|c|}{ Control } & O-E & Varlance & Welght & $\begin{array}{l}\text { Hazard Ratio } \\
\text { Expe(O-E) } / \mathrm{V}\} \text {, Flxed, } 95 \% \mathrm{Cl}\end{array}$ & \multicolumn{2}{|c|}{$\begin{array}{c}\text { Hazard Ratio } \\
\text { Exp[(O-E) } / \text { V], Flxed, } 95 \% \mathrm{CI}\end{array}$} \\
\hline \multicolumn{11}{|c|}{ 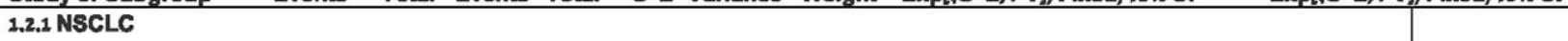 } \\
\hline Herbst 2007 & 0 & 40 & 0 & 41 & -5.13 & 12.34 & $0.6 \%$ & $0.66[0.38,1.15]$ & & \\
\hline Reck 2009 & 0 & 329 & 0 & 327 & -25.21 & 155.14 & $7.8 \%$ & $0.85[0.73,0.99]$ & & \\
\hline $\begin{array}{l}\text { Sandler } 2006 \\
\text { Subtotal }(95 \% \mathrm{Cl})\end{array}$ & 0 & $\begin{array}{l}417 \\
786\end{array}$ & 0 & $\begin{array}{l}433 \\
801\end{array}$ & -70.59 & 169.88 & $\begin{array}{l}8.5 \% \\
16.9 \%\end{array}$ & $\begin{array}{l}0.66[0.57,0.77] \\
0.74[0.67,0.82]\end{array}$ & & \\
\hline \multicolumn{11}{|c|}{$\begin{array}{l}\text { Heterogeneity: Chi }{ }^{2}=5.37, \text { df }-2(P=0.07) ; 1^{2}=63 \% \\
\text { Test for overall effect: } Z=5.50(P<0.00001)\end{array}$} \\
\hline \multicolumn{11}{|l|}{ 1.2.2 colon cancer } \\
\hline Hurwitz 2004 & 0 & 402 & 0 & 411 & -70.02 & 113.63 & $5.7 \%$ & $0.54[0.45,0.65]$ & & \\
\hline Kabbinavar 2005 & 0 & 104 & 0 & 105 & -18.24 & 26.32 & $1.3 \%$ & $0.50[0.34,0.73]$ & & \\
\hline Saltz 2008 & 0 & 699 & 0 & 701 & -37.26 & 199.96 & $10.0 \%$ & $0.83[0.72,0.95]$ & & \\
\hline $\begin{array}{l}\text { Tebbutt } 2010 \\
\text { Subtotal (95\% Cl) }\end{array}$ & 0 & $\begin{array}{r}157 \\
1362\end{array}$ & 0 & $\begin{array}{r}156 \\
1373\end{array}$ & -33.93 & 73.44 & $\begin{array}{r}3.7 \% \\
20.7 \%\end{array}$ & $\begin{array}{l}0.63[0.50,0.79] \\
0.68[0.62,0.75]\end{array}$ & & \\
\hline \multicolumn{11}{|c|}{$\begin{array}{l}\text { Heterogeneity: Chi }{ }^{2}-16.90, \text { df }-3(P=0.0007) ; 1^{2}=82 \% \\
\text { Test for overall effect: } Z-7.84(P<0.00001)\end{array}$} \\
\hline \multicolumn{11}{|l|}{ 1.2.3 Breast cancer } \\
\hline Gray R 2009 & 0 & 347 & 0 & 326 & -78.27 & 153.23 & $7.7 \%$ & $0.60[0.51,0.70]$ & & \\
\hline Miles $201015 \mathrm{mg} / \mathrm{kg}$ & 0 & 247 & 0 & 241 & -33.3 & 83.16 & $4.2 \%$ & $0.67[0.54,0.83]$ & & \\
\hline Robert anthra+tax 2010 & 0 & 415 & 0 & 207 & -38.75 & 86.83 & $4.3 \%$ & $0.64[0.52,0.79]$ & & \\
\hline $\begin{array}{l}\text { Robert Cap } 2010 \\
\text { Subtotal ( } 95 \% \text { Cl) }\end{array}$ & 0 & $\begin{array}{r}409 \\
1428\end{array}$ & 0 & $\begin{array}{l}206 \\
980\end{array}$ & -36.21 & 96.83 & $\begin{array}{r}4.8 \% \\
21.0 \%\end{array}$ & $\begin{array}{l}0.69[0.56,0.84] \\
0.64[0.58,0.71]\end{array}$ & & \\
\hline \multicolumn{11}{|c|}{$\begin{array}{l}\text { Heterogeneity: Chi }{ }^{2}=1.32, \text { df }=3(P=0.73) ;\left.\right|^{2}=0 \% \\
\text { Test for overall effect: } Z-9.10(P<0.00001)\end{array}$} \\
\hline \multicolumn{11}{|c|}{ 1.2.4 Renal cell carcinoma } \\
\hline Escudier 2007 & 0 & 327 & 0 & 322 & -52.93 & 114.56 & $5.7 \%$ & $0.63[0.52,0.76]$ & & \\
\hline $\begin{array}{l}\text { Rini } 2008 \\
\text { Subtotal (95\% CI) }\end{array}$ & 0 & $\begin{array}{l}369 \\
696\end{array}$ & 0 & $\begin{array}{l}363 \\
685\end{array}$ & -53.22 & 162.01 & $\begin{array}{r}8.1 \% \\
13.8 \%\end{array}$ & $\begin{array}{l}0.72[0.62,0.84] \\
0.68[0.61,0.77]\end{array}$ & & \\
\hline \multicolumn{11}{|c|}{$\begin{array}{l}\text { Heterogeneity: Chi }{ }^{2}=1.20, \text { df }-1(P-0.27) ; 1^{2}=16 \% \\
\text { Test for overall effect: } Z=6.38(P<0.00001)\end{array}$} \\
\hline \multicolumn{11}{|l|}{ 1.2.5 Gastric cancer } \\
\hline $\begin{array}{l}\text { Ohtsu } 2011 \\
\text { Subtotal (95\% Cl) }\end{array}$ & 0 & $\begin{array}{l}387 \\
387\end{array}$ & 0 & $\begin{array}{l}387 \\
387\end{array}$ & -34.98 & 156.75 & $\begin{array}{l}7.8 \% \\
7.8 \%\end{array}$ & $\begin{array}{l}0.80[0.68,0.94] \\
0.80[0.68,0.94]\end{array}$ & & \\
\hline $\begin{array}{l}\text { Total events } \\
\text { Heterogeneity: Not app } \\
\text { Test for overall effect: }\end{array}$ & $\begin{array}{l}\text { cable }^{0} \\
=2.79\left(\mathrm{P}=C^{2}\right.\end{array}$ & .005) & 0 & & & & & & & \\
\hline \multicolumn{11}{|l|}{ 1.2.6 Pancreatlc cancer } \\
\hline $\begin{array}{l}\text { Van Cutsem } 2009 \\
\text { Subtotal (9s\% Cl) }\end{array}$ & 0 & $\begin{array}{l}306 \\
306\end{array}$ & 0 & $\begin{array}{l}301 \\
301\end{array}$ & -40.99 & 130.25 & $\begin{array}{l}6.5 \% \\
6.5 \%\end{array}$ & $\begin{array}{l}0.73[0.61,0.87] \\
0.73[0.61,0.87]\end{array}$ & & \\
\hline $\begin{array}{l}\text { Total events } \\
\text { Heterogeneity: Not app } \\
\text { Test for overall effect: }\end{array}$ & $\begin{array}{l}\text { cable }^{0} \\
=3.59\left(\mathrm{P}=C^{\circ}\right.\end{array}$ & $.0003)$ & 0 & & & & & & & \\
\hline \multicolumn{11}{|l|}{ 1.2.7 prostate cancer } \\
\hline $\begin{array}{l}\text { Kelly } 2010 \\
\text { Subtotal (95\% CI) }\end{array}$ & 0 & $\begin{array}{l}524 \\
524\end{array}$ & 0 & $\begin{array}{l}526 \\
526\end{array}$ & -60.41 & 231.15 & $\begin{array}{l}11.6 \% \\
11.6 \%\end{array}$ & $\begin{array}{l}0.77[0.68,0.88] \\
0.77[0.68,0.88]\end{array}$ & & \\
\hline $\begin{array}{l}\text { Total events } \\
\text { Heterogeneity: Not app } \\
\text { Test for overall effect: }\end{array}$ & $\begin{array}{l}\text { cable } \\
=3.97(P<C\end{array}$ & $.0001)$ & 0 & & & & & & & \\
\hline 1.2.8 Melanoma & & & & & & & & & & \\
\hline $\begin{array}{l}\text { Kim } 2011 \\
\text { Subtotal (95\% Cl) }\end{array}$ & 0 & $\begin{array}{l}143 \\
143\end{array}$ & 0 & $\begin{array}{l}71 \\
71\end{array}$ & -8.61 & 34.64 & $\begin{array}{l}1.7 \% \\
1.7 \%\end{array}$ & $\begin{array}{l}0.78[0.56,1.09] \\
0.78[0.56,1.09]\end{array}$ & & \\
\hline $\begin{array}{l}\text { Total events } \\
\text { Heterogenelty: Not app } \\
\text { Test for overall effect: }\end{array}$ & cable & & 0 & & & & & & & \\
\hline Total $(95 \% \mathrm{Cl})$ & & 5622 & & 5124 & & & $100.0 \%$ & $0.71[0.68,0.74]$ & $\mathbf{\theta}$ & \\
\hline Total events & 0 & & 0 & & & & & & & \\
\hline $\begin{array}{l}\text { Heterogeneity: Chi }-3 \\
\text { Test for overall effect: }\end{array}$ & $\begin{array}{l}07, \mathrm{df}-16 \\
15.61(\mathrm{P}<\end{array}$ & $\begin{array}{l}2.0 .004 \\
0.000011\end{array}$ & $11_{1}^{2}=54 \%$ & & & & & & $\begin{array}{cc} & 1 \\
0.5 & 0.7 \\
\text { avours experimental }\end{array}$ & ${ }^{i} \quad 1.5$ \\
\hline
\end{tabular}

Figure 3. Progression free survival.

doi:10.1371/journal.pone.0051780.g003 


\section{$\underline{\text { a: } \text { breast cancer } 2^{\text {nd }} \text { line PFS }}$}

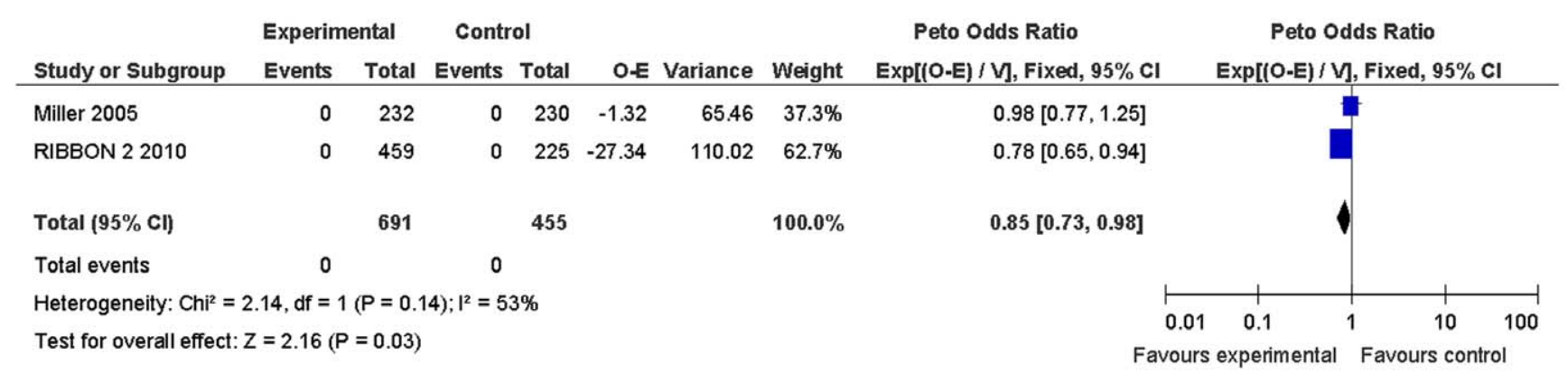

\section{$\underline{\text { b: } \text { breast cancer } 2^{\text {nd }} \text { line } \text { OS }}$}

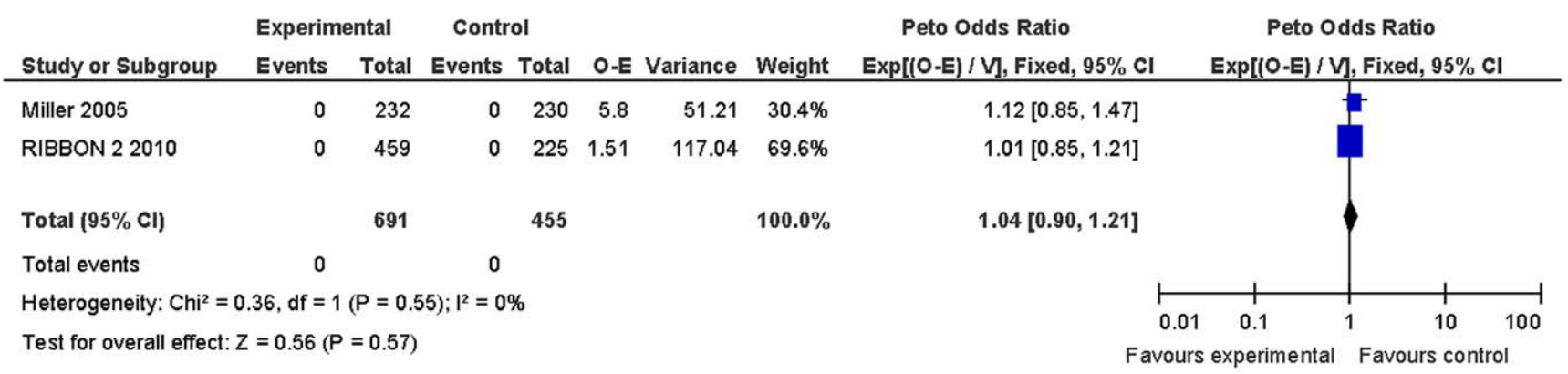

Figure 4. Progression free survival and overall survival in 2 nd line metastatic breast cancer. doi:10.1371/journal.pone.0051780.g004

perforation was significant only in colon cancer RR3.99 (95\%CI1.34-11.85 $\mathrm{p}=0.01)$. There was an increased risk of arterial thromboembolic events in breast cancer RR-5.97 (95\% CI 1.07-33.22), and in RCG RR 6.55 (95\%CI 1.5-28.59).
The calculated number needed to harm upon the incidence of fatal events is 117 , i.e., for one fatal event in the bevacizumab arm 117 patients would need to be treated (RR 1.4).

Table 2. Toxicity analysis.

\begin{tabular}{|c|c|c|c|c|}
\hline Event & $\underline{\mathbf{R R}}$ & $95 \% \mathrm{Cl}$ & $\underline{\mathbf{P}}$ & $12(\%)$ \\
\hline Adverse event $>$ G2 & 1.2 & $(1.15-1.24)$ & $<0.00001$ & 90 \\
\hline Proteinuria & 7.08 & $(4.54-11.04)$ & $<0.00001$ & 0 \\
\hline HTN & 4.96 & $(3.82-6.44)$ & $<0.00001$ & 0 \\
\hline Hemorrhage & 1.34 & $(1.02-1.76)$ & 0.28 & 16 \\
\hline Venous thromboembolic event & 1.07 & $(0.9-1.27)$ & 0.1 & 34 \\
\hline Arterial ischemic event & 1.32 & $(0.98-1.78)$ & 0.13 & 30 \\
\hline GI perforation & 2.3 & $(1.34-3.95)$ & 0.66 & 0 \\
\hline Fatal events & 1.48 & $(1.11-1.98)$ & 0.02 & 52 \\
\hline Fatal pulmonary hemorrhage (lung studies) & 5.65 & $(1.26-25.26)$ & 0.02 & $\mathbf{0}$ \\
\hline
\end{tabular}


The results of our analysis of Bevacizumab as second line therapy concurrently with chemotherapy in breast cancer patients showed the same trend of improved PFS and lack OS benefit, a fact that may support the use of Bevacizumab in advanced lines and could be more cost effective.

\section{Limitations}

Limitations of our analysis should be acknowledged. The dissimilarity in the chemotherapy regimens, dosing and schedules between the various studies confound the analysis. The heterogeneous length of treatment and follow up contribute to the asymmetry as well. Also, the small number of included trials for each disease makes the outcomes more prone to be influenced by a potential publication bias. We attempted to avoid such bias by searching and including conference proceedings, databases of ongoing trials and unpublished data. The biological rationale to combine all studies in order to assess Bevacizumab universal effect might offset this limitation.

\section{Implications for clinical practice}

This analysis showed an overall survival benefit. It reinforces the use of Bevacizumab in colon and lung cancer.

Regarding breast cancer, the FDA recently revoked its approval of the use of Bevacizumab. Our data supports this decision at this time. Promising data supporting the use of Bevacizumab in the neoadjuvant treatment of locally advanced breast cancer [56-57] emphasizes the need for further studies in the search of predictive markers.

Analysis of databases should be attempted in order to estimate the effect of Bevacizumab on non trial populations, as was recently published by Zhu et al [59].

\section{Implications for research}

Many questions still remain regarding the effect of Bevacizumab as maintenance therapy compared with Bevacizumab at disease

\section{References}

1. Eskens FA, Sleijfer S (2008) the use of Bevacizumab in colorectal, lung, breast, renal and ovarian cancer. Where does it fit? European journal of cancer 33: 2350-2356

2. Rosen LS, Ashurst HL, Chap L (2010) targeting signal transduction pathways in metastatic breast cancer a comprehensive review. Oncologist 15: 216-235.

3. Weidner N, Folkman J, Pazza F, Bevilacqua P, Allred EN, et al. (1992) Tumor angiogenesis: a new significant and independent prognostic indicator in early stage breast carcinoma. J Natl Cancer Inst 84:1875-1887.

4. Linderholm B, Grankvist K, Wilking N, Johansson M, Tavelin B, et al. (2000) Correlation of vascular endothelial growth factor content with recurrences, survival, and first relapse site in primary node-positive breast carcinoma after adjuvant treatment. J Clin Oncol 18:1423-1431.

5. Kerbel RS (2008) Tumor angiogenesis. N Engl J Med 358: 2039-49.

6. Brufsky A (2010) Angiogenesis inhibition and metastatic breast cancer: cases and answers. Presentation.

7. Hurwitz H, Fehrenbacher L, Novotny W, Cartwright T, Hainsworth J, et al. (2004) Bevacizumab plus Irinotecan, Flouorouracil and Leucovorin for metastatic colorectal cancer. NEJM 350: 2335-2342.

8. Saltz LB, Clarke S, Diaz-Rubio S, Scheithauer W, Figer A, et al. (2008) Bevacizumab in combination with oxaliplatin based chemotherapy as first line therapy in metastatic colorectal cancer: a randomized phase III study. JCO 26(12): 2013-2019.

9. Kabbinavar F, Hurwitz H, Fehrenbacher L, Meropol NJ, Novotny WF, et al. (2003) Phase II randomized trial comparing Bevacizumab plus Fluorouracil(FU)/Leucovorin( $\mathrm{LV}$ ) with $\mathrm{FU} / \mathrm{LV}$ alone in patients with metastatic colorectal cancer. JCO 21(1): 60-65.

10. Kabbinavar FF, Schulz J, McCleod M, Patel T, Hamm JT, et al. (2005) addition of Bevacizumab to bolus Fluorouracil and Leucovorin in first line metastatic colorectal cancer: results of randomized phase II trial. JCO 23(16): 3697-3705.

11. Kabbinavar FF, Hambleton J, Mass RD, Hurwitz HI, Berqsland E, et al. (2005) combined analysis of efficacy: the addition of Bevacizumab to fluorouracil/ leucovorin improves survival for patients with metastatic colorectal cancer. JCO: $23 ; 3706-3712$ progression and the optimal schedule and type of chemotherapy in each disease. Also, Bevacizumab is a nonspecific agent without any well defined predictive markers.

Data supporting the use of Bevacizumab as neoadjuvant therapy in breast cancer patients have been published recently [57-58] and therefore further studies should be considered in the search for predictive markers.

Analysis of the trials already published in search of predictive markers through a patient based metaanalysis could help define possible predictive markers for future validation studies.

Finally, randomized controlled trials should have longer followup to appraise the long-term toxicity of Bevacizumab.

\section{Conclusion}

In conclusion, our results suggest that adding Bevacizumab to chemotherapy results in a small but significant effect on OS and a significant PFS advantage in the advanced solid tumors included in this analysis.

\section{Supporting Information}

\section{Appendix S1 Search phrase. (DOC)}

\section{Acknowledgments}

Dr David H Johnson

Dr Herbert Hurwitz

\section{Author Contributions}

Conceived and designed the experiments: LA IBA LV LL SS. Performed the experiments: LA IBA LV LL SS. Analyzed the data: LA IBA LV LL SS. Contributed reagents/materials/analysis tools: LA IBA LV LL SS. Wrote the paper: LA IBA LV LL SS.

12. Giantonio BJ, Catalano PJ, Meropol NJ, O’Dwyer PJ, Mitchell EP, et al. (2007) Bevacizumab in combination with FOLFOX4 for previously treated metastatic colorectal cancer: results from ECOG E3200. JCO 25(12);1539-1544.

13. Tebbutt NC, Wilson K, Gebski BJ, Cummins MM, Zannino D, et al. (2010) Capecitabine, Bevacizumab and Mitomycin in first line treatment of metastatic colorectal cancer: results of the Australian gastrointestinal trials group randomized phase III MAX study. JCO 28(19): 3191-3198.

14. Wagner AD, Arnold D, Grothey AA, Haerting J, Unverzaqt S, et al. (2009) antiangiogenic therapies for metastatic colorectal cancer (review). The Cochrane database (3).

15. Gridelli C, Maione P, Rossi A, De Marinis F (2007) The role of Bevacizumab in the treatment of NSCLC: current indications and future developments. The oncologist: 12:1183-1193.

16. Reck M, Von Pawel J, Zatloukal P, Ramlau R, Gorbounova V, et al. (2009) Phase III trial of Cisplatin plus Gemcitabine with either placebo or bevacizumab as first line therapy for non-squamous NSCLC: AVAiL. JCO 27(8): 1227-1234.

17. Reck M, Von Pawel J, Zatloukal P, Ramlau R, Gorbounova V, et al. (2010) overall survival with cisplatin-gemcitabina and Bevacizumab or placebo as first line therapy for non squamous NSGLC: results from a randomized phase III trial (AVAiL). Ann of oncology 21: 1804-1809.

18. Sandler A, Gray R, Perry MC, Brahmer J, Schiller JH, et al. (2006) PaclitaxelCarboplatin alone or with Bevacizumab for NSCLC. NEJM: 355:2542-2550.

19. Johnson DH, Fehrenbacher L, Novotny WF, Herbst RS, Nemunaitis IJ, et al. (2004) Randomized phase II trial comparing Bevacizumab plus Carboplatin and Paclitaxel with Carboplatin and Paclitaxel alone in previously untreated locally advanced or metastatic NSCLC. JCO 22(11):2184-2191.

20. Herbst RS, O'Neill VJ, Fehrenbacher L, Belani CP, Bonomi PD, et al. (2007) phase II study of efficacy and safety of bevacizumab in combination with chemotherapy or Erlotinib compared with chemotherapy alone for treatment of recurrent or refractory NSCLC. JCO 25(30):4743-4750.

21. Scagliotti GV, Parikh P, Von Pawel J, Biesma B, Vansteenkiste J, et al. (2008) phase III study comparing Cisplatin plus Gemcitabine with Cisplatin plus Pemetrexed in chemotherapy-naïve patients with advanced NSCLC. JCO 26(21):3543-3551. 
22. Miller KD, Chap LI, Holmes FA, Cobleigh MA, Marcom PK, et al. (2005) Randomized phase III trial of Capecitabine compared with Bevacizumab plus Capecitabine in patient with previously treated metastatic breast cancer. JCO 23:792-799.

23. Miller K, Wang M, Gralow J, Dickler M, Cobleigh M, et al. (2007) Paclitaxel with Bevacizumab versus Paclitaxel alone in metastatic breast cancer. NEJM 357:2666-2676

24. Gray R, Bhattacharya S, Boden C, Miller K, Comis RL, et al. (2009) Independent review of E2100: a phase III trial of Bevacizumab plus Paclitaxel versus Paclitaxel in women with metastatic breast cancer. JCO 27:4966-4972.

25. Robert NJ, Dieras V, Glaspy J, Brufsky A, Bondarenko I, et al. (2009) RIBBON -1: randomized, double blind, placebo controlled phase III trial of chemotherapy with or without Bevacizumab for first line treatment of HER2 negative locally recurrent or metastatic breast cancer. ASCO presentation. JCO 27:15sabst 1005 .

26. Robert A (2009) clinical benefit and time to response in RIBBON-1 a randomized, double blind, phase III trial of chemotherapy with or without Bevacizumab for first line treatment of HER2 negative locally recuurent or metastatic breast cancer. SABCS 2009

27. Robert NJ, Dieras V, Glaspy J, Brufsky A, Bondarenko I, et al. (2011) RIBBON1: Randomized, Double-Blind, Placebo-Controlled, Phase III Trial of Chemotherapy With or Without Bevacizumab for First-Line Treatment of Human Epidermal Growth Factor Receptor 2-Negative, Locally Recurrent or Metastatic Breast Cancer. JCO 29(10):1252-1260.

28. Miles DW, Chan A, Dirix LY, Cortes J, Pivot X, et al. (2010) Phase III study of Bevacizumab plus Docetaxel campared with placebo plus docetaxel for the first line treatment of human epidermal growth factor receptor-2-negative metastatic breast cancer. JCO 28(20):3239-3247.

29. Brufsky A (2009) RIBBON-2: a randomized, double blind, placebo controlled phase III evaluating the efficacy and safety of Bevacizumab in combination with chemotherapy for second line treatment of HER2 negative metastatic breast cancer. SABCS.

30. Brufsky A, Rivera RR, Hurvitz AA, Bonderenko IN, Smirnov V, et al. (2010) progression free survival in patient subgroups in RIBBON-2, a phase III trial of chemotherapy plus or minus Bevacizumab for second line treatment of HER2 negative locally recurrent or metastatic breast cancer. ASCO presentation. JCO 28: $15 \mathrm{~s}$ : abstr 1021.

31. Brufsky AM, Hurvitz SA, Perez EA, Yamamoto A, Valero V, et al. (2012) final overall survival (OS) and safety analyses of RIBBO-2 a randomized phase III trial of Bevacizumab versus placebo combined with second line chemotherapy in HER2 negative Bevacizumab naïve metastatic breats cancer. ASCO presentation. JCO 30 suppl 27 abstr 100.

32. O'Shaughnessy J, Miles D, Gray RJ, Perez EA, Diaras V, et al. (2010) A metaanalysis of overall survival data from three randomized trials of Bevacizumab and first line chemotherapy as treatment for patients with metastatic breast cancer. ASCO JCO 28:15s: abstr 1005.

33. Yang JC, Haworth L, Sherry RM, Hwu P, Schwartzentruber DJ, et al. (2003) A randomized trial of Bevacizumab an anti-vascular endothelial growth factor antibody for metastatic renal cancer. NEJM 349(5);427-434.

34. Rini BL, Halabi S, Rosenberg JE, Stadler WM, Vaena DA, et al. (2010) phase III trial of Bevacizumab plus interferon alfa versus interferon alfa monotherapy in patients with metastatic renal cell carcinoma final results of CALGB 90206. JCO 28;1-7.

35. Rini BL, Halabi S, Rosenberg JE, Stadler WM, Vaena DA, et al. (2008) Bevacizumab plus interferon alfa compared with interferon alfa monotherapy in patients with metastatic renal cell carcinoma: CALBG 90206. JCO 26(33): 5422-5428.

36. Escudier B, Pluzanka A, Koralewski P, Ravaud A, Bracarda S, et al. (2007) Bevacizumab plus interferon alfa-2a for treatment of metastatic renal cell carcinoma: a randomized double blind phase III trial. Lancet 370;2103-2111.

37. Escudier B, Bellmunt J, Negrier S, Bajetta E, Melichar B, et al. (2010) phase III trial of Bevacizumab plus interferon alfa -2a in patients with metastatic renal cell carcinoma (AVOREN): final analysis of overall survival. JCO 28(13):2144-2150.

38. Van Cutsem E, Vervenne WL, Bennouna J, Humblet Y, Gill S, et al. (2009) Phase III Trial of Bevacizumab in Combination With Gemcitabine and Erlotinib in Patients with Metastatic Pancreatic Cancer. JCO 27(13):2231-2237.

39. Kindler HL, Niedzwiecki D, Hollis D, Sutherland S, Schraq D, et al. (2010) Gemcitabine plus Bevacizumab Compared with Gemcitabine plus Placebo in Patients with Advanced Pancreatic Cancer: Phase III Trial of the Cancer and Leukemia Group B (CALGB 80303). JCO 28(22):3617-3622.
40. Shah MA, Ramanathan RK, Ilson DH, Levnor A, D'Adamo D, et al. (2006) Multicenter Phase II Study of Irinotecan, Cisplatin, and Bevacizumab in Patients With Metastatic Gastric or Gastroesophageal Junction Adenocarcinoma. JCO 24:5201-5206.

41. Atsushi O, Shah MA, Van Cutsem E, Rha SY, Sawaki A, et al. (2011) Bevacizumab in Combination With Chemotherapy As First-Line Therapy in Advanced Gastric Cancer: A Randomized, Double-Blind, Placebo-Controlled Phase III Study JCO 29:3968-3976.

42. Kelly WK, Halabi S, Carducci M, George D, Mahoney JF, et al. (2012) A randomized, double-blind, placebo-controlled phase III trial comparing docetaxel, prednisone, and placebo with docetaxel, prednisone, and bevacizumab in men with metastatic castration-resistant prostate cancer (mCRPC): Survival results of CALGB 90401. JCO 30(13): 1534-1540.

43. Kim KB, Sosman JA, Fruehauf JP, Linette GP, Markovic SN, et al. (2012) BEAM: a randomized phase II study evaluating the activity of Bevacizumab in combination with Carboplatinum plus Paclitaxel in patients with previously untreated advanced Melanoma. JCO 30(1): 34-41.

44. Scartozzi M, Galizia E, Chiorrini S, Giampierri R, Berardi R, et al. (2009) arterial HTN correlates with clinical outcome in colorectal patients treated with first line Bevacizumab. Annals of oncology 20(2): 227-230.

45. Bono P, Elfving H, Utriainen T, Osterlund P, Saarto T, et al. (2009) HTN and clinical benefit of Bevacizumab in the treatment of advanced renal cell carcinoma. Annals of oncology 20(2);393-394.

46. Dahlberg SE, Sandler AB, Brahmer JR, Schiller JH, Johnson DH, et al. (2010) clinical course of advanced non small cell lung cancer in patients experiencing HTN during treatment with Bevacizumab in combination with carboplatin and paclitaxel in ECOG 4599. JCO 28(6);949-954.

47. Schneider BP, Wang M, Radovich M, Sledge GW, Badve S, et al. (2008) association of vascular endothelial growth factor and vascular endothelial growth factor receptor 2 genetic polymorphisms with outcome in a trial of paclitaxel compared with Paclitaxel plus Bevacizumab in advanced breast cancer: ECOG 2100. JCO 26(28);4672-4678.

48. Chan A, Miles DW, Pivot X (2010) Bevacizumab in combination with taxanes for the first line treatment of breast cancer annals of oncology. 21(12): 23052315 .

49. Golfinopoulos V, Salanti G, Pavilidis N, Ioannidis JP (2007) survival and disease progression benefits with treatment regimens for advanced colorectal cancer: a meta-analysis. The lancet oncol 8;898-911.

50. Welch S, Spithoff K, Rumble RB, Maroun J (2010) Bevacizumab combined with chemotherapy for patients with advanced colorectal cancer: a systematic review. Annal of oncology 21(6): 1152-1162.

51. Loupakis F, Bria E, Vaccaro V, Cuppone F, Millela M, et al. (2010) magnitude of benefit of the addition of Bevacizumab to first line chemotherapy for metastatic colorectal cancer: meta-analysis of randomized clinical trials. journal of experimental \& clinical cancer research 29:58.

52. Ocaña A, Amir E, Vera F, Eisenhauer EA, Tannock IF, et al. (2011) Addition of Bevacizumab to Chemotherapy for Treatment of Solid Tumors: Similar Results But Different Conclusions. JCO 29(3): 254-256.

53. Broglio KR, Berry DA (2009) detecting an overall survival benefit that is derived from progression free survival. JNCI 101;1642-1649.

54. Ranpura V, Hapani S, Wu S (2011) Treatment-Related Mortality With Bevacizumab in Cancer Patients A Meta-analysis. JAMA 305(5):487-494

55. Hurwitz HI, Saltz LB, Van Cutsem E, Cassidy J, Weidenmann J, et al. (2011) Venous Thromboembolic Events With Chemotherapy Plus Bevacizumab: A Pooled Analysis of Patients in Randomized Phase II and III Studies. JCO 29(13): 1757-1764.

56. Vredenburgh JJ, Desjardins A, Herndon JE 2nd, Marcello J, Reardon DA, et al. (2007) Bevacizumab plus Irinotecan in recurrent glioblastoma multiforme. JCO 25:4722-4729.

57. Bear HD, Tang G, Rastoqi P, Geyer CE Jr, Robidoux A, et al. (2012) Bevacizumab added to neoadjuvant chemotherapy forbreast cancer. NEJM: 2012:366:310-320

58. Von Minckwitz G, Eidtmann H, Rezai M, Fasching PA, Tesch H, et al. (2012 Neoadjuvant chemotherapy and Bevacizumab for HER2 negative breast cancer. NEJM: 366:299-309

59. Zhu J, Sharma DB, Gray SW, Chen AB, Weeks JC, et al. (2012) Carboplatin and Paclitaxel with vs without Bevacizumab in older patients with advanced non small cell lung cancer. JAMA 307(15): 1593-1601. 